\title{
An International Survey of the Wellbeing of Employees in the Business Process Outsourcing Industry
}

\author{
Andrew Smith, Hugo Smith \\ Cardiff University, Cardiff, UK \\ Email: smithap@cardiff.ac.uk
}

How to cite this paper: Smith, A., \& Smith, H. (2017). An International Survey of the Wellbeing of Employees in the Business Process Outsourcing Industry. Psychology, 8, 160-167.

http://dx.doi.org/10.4236/psych.2017.81010

Received: November 22, 2016

Accepted: January 17, 2017

Published: January 20, 2017

Copyright $\odot 2017$ by authors and Scientific Research Publishing Inc. This work is licensed under the Creative Commons Attribution International License (CC BY 4.0).

http://creativecommons.org/licenses/by/4.0/

\begin{abstract}
The project described in this article was part of a larger program on wellbeing at work and involved an international survey of staff in the business process outsourcing industry. The survey used the Smith Wellbeing Questionnaire (SWELL) and the results showed that this measured both positive and negative aspects of wellbeing. The sample reported high levels of stress which was predicted by job demands and lack of control and support. High levels of control/support were associated with greater job satisfaction.
\end{abstract}

\section{Keywords}

Business Process Outsourcing, Wellbeing, Stress, Fatigue

\section{Introduction}

The study described here was part of a program of research on wellbeing at work. This started with research that aimed to address "What is a good job?" (Smith et al., 2011). A key finding from that project was that one has to examine both positive and negative outcomes rather than inferring one from the other. This view fits with research showing that positive and negative emotions involved different brain processes (Watson, Clark, \& Tellegen, 1988). Much of our previous research on wellbeing at work has focused on negative outcomes such as stress and fatigue (Smith et al., 2000; Smith, Allen \&Wadsworth, 2006). In contrast, research on wellbeing largely deals with life satisfaction, happiness and positive affect (Diener et al., 1999).

Another feature of the present research was that it used a process model similar to those developed in stress (Mark \& Smith, 2008, 2011, 2012) and fatigue research (Smith, 2010). Such models start with job characteristics that may influence wellbeing (e.g. negative characteristics such as job demands; positive cha- 
racteristics such as control and support), appraisals (e.g. perceived stress; job satisfaction) and outcomes (health outcomes such as anxiety and depression, musculoskeletal disorders and illnesses caused or made worse by work; absenteeism; accidents; presenteeism and performance efficiency). In addition to work-related factors it is important to measure individual characteristics (e.g. positive personality and healthy lifestyle). It is also important to assess life outside of work and work-life balance.

In order to measure the multiple constructs described above it is necessary to use short scales. This approach has been used by Williams (2012) and many of the items in the present survey were taken from the Wellbeing Process Questionnaire (WPQ). These items have been shown to be highly correlated with the longer scales from which they were derived and to show the predicted associations between job characteristics, appraisals and outcomes (Williams \& Smith, $2013,2016)$. In other words, the survey measured both positive and negative aspects of well-being (job characteristics; appraisals; and outcomes) using single items which had been shown to correlate highly with longer scales. These single items also showed the same predictive validity as the longer scales (Williams \& Smith, 2013, 2016).

A final aim of the project was to extend the sample to consider a very different occupation in several countries. Much of the previous research on wellbeing has used public sector employees (e.g. nurses; teachers and university staff). Business process outsourcing is a growing industry and now covers many areas traditionally done in-house by the financial sector or even the public sector. These companies often recruit staff from the host organization and are under pressure to demonstrate cost and efficiency changes. The workers are usually in teams and this hierarchical structure is known to generate high levels of stress. The present online survey was the first to examine wellbeing in this sector and the sample were working in the UK, the USA and South Africa.

\section{Method}

\subsection{Ethical Approval}

The study was carried out with the approval of the School of Psychology ethics committee, Cardiff University and the informed consent of the participants.

\subsection{Sample}

The sample were recruited from two companies who were concerned with financial outsourcing. The staff of the two companies were sent an e-mail link to the online survey. The participants carried out a range of jobs (e.g. operations manager; team leader; administrator; and financial controller). One hundred and fifty one participants completed the survey (mean age $=34.1$ years; $65.8 \%$ male).

\subsection{The Survey}

The online survey was conducted using Qualtrics software. It started with in- 
formation about the study and was followed by a consent form which stated that participation was voluntary, questions could be avoided and that the volunteer could withdraw at any time. It was also stated that the data would be held anonymously and that it would be impossible to identify participants. The volunteers then completed the survey ( 21 questions; most with a 10 point response scale) which is shown in Table 1 . On completion the volunteers were shown a debrief statement which repeated the aims of the study and thanked them for their participation.

\subsection{Statistical Analyses}

Initial factor analyses examined the structure of the questionnaire. Descriptive analyses then examined the frequencies in the different response categories. Following this the response scales were dichotomised into high/low groups (usually at a threshold of $<7$ versus 7 and above). Regression analyses were then conducted to determine the predictors of the appraisals and outcomes.

\section{Results}

\subsection{Factor Structure and Reliability}

Factor analysis with varimax rotation revealed two factors representing positive wellbeing (e.g. job control/support; job satisfaction and happiness at work Cronbach alpha $=0.81$ ) and negative wellbeing (e.g. job demands; stress at work; and anxiety/depression due to work - Cronbach alpha $=0.65)$.

\subsection{Descriptive Statistics}

The frequencies for each response category for each question are shown in Table 1. The descriptive statistics shown in Table 1 suggest that the sample had high stress levels, and reported mental health problems. However, levels of job satisfaction and happiness were also high. These issues were examined by creating high and low categories and these are described in the next section.

\subsection{Dichotomised Variables}

The scales shown above are often dichotomized to produce high and low categories. For example, stress at work would be split at 7 and above (high stress) and 6 and below (low stress). Using this approach one finds that $38.8 \%$ of the sample reported high stress and $18.4 \%$ high anxiety/depression due to work. These results confirm that the staff who took part in the survey have high levels of stress and mental health problems. If one examines positive wellbeing at work using a similar approach, $87.5 \%$ report high job satisfaction and $88.8 \%$ report high levels of happiness at work.

\subsection{Predictors of Appraisals and Outcomes}

Stress at work was found to be correlated with noise, demands, lack of control/ support and negative health-related behaviors. Multiple regression showed that high job demands and lack of control/support were the only significant predic- 
Table 1. Questions in the survey and frequencies (\%) in response categories.

Health-related behaviours

A healthy lifestyle involves taking exercise, eating a balanced diet, not smoking, not drinking excessive amounts of alcohol, and not being overweight. To what extent do you have a healthy life style?

$\begin{array}{llllllllll}\text { Not at all } & & & & & & & & \text { Very much so } \\ 1 & 2 & 3 & 4 & 5 & 6 & 7 & 8 & 9 & 10 \\ 2.6 & 2.6 & 1.3 & 3.2 & 11.5 & 14.7 & 24.4 & 27.6 & 7.1 & 5.1\end{array}$

Personality

People often describe themselves as being positive ("seeing" the glass as half full) or negative ("seeing the glass as half empty"). How would you describe yourself? Very negative

Very positive

$\begin{array}{llllllllll}1 & 2 & 3 & 4 & 5 & 6 & 7 & 8 & 9 & 10 \\ 0.6 & 0 & 0.6 & 3.2 & 9.0 & 6.4 & 17.9 & 30.1 & 16.7 & 15.4\end{array}$

Thinking about the last 6 months:

Life satisfaction

How satisfied are you with life in general?

Not at all Very much so

$\begin{array}{llllllllll}1 & 2 & 3 & 4 & 5 & 6 & 7 & 8 & 9 & 10\end{array}$

$\begin{array}{llllllllll}1.3 & 0 & 3.8 & 4.5 & 9.6 & 14.6 & 24.2 & 23.6 & 14.0 & 4.5\end{array}$

Life stress

How much stress have you had in your life in general?

\begin{tabular}{llllllllll}
\multicolumn{3}{c}{ Very little } & & & & & & & A g \\
1 & 2 & 3 & 4 & 5 & 6 & 7 & 8 & 9 & 10 \\
0 & 7.6 & 7.0 & 6.4 & 16.6 & 14.6 & 17.2 & 16.6 & 10.8 & 3.2
\end{tabular}

Happiness

Would you say you are generally happy?

Not at all Very much so

$\begin{array}{llllllllll}1 & 2 & 3 & 4 & 5 & 6 & 7 & 8 & 9 & 10\end{array}$

$\begin{array}{llllllllll}1.3 & 0.6 & 1.9 & 3.2 & 13.5 & 12.9 & 16.1 & 26.5 & 19.4 & 4.5\end{array}$

Anxious/Depressed

Would you say that you generally feel anxious or depressed?

Not at all Very much so

$\begin{array}{llllllllll}1 & 2 & 3 & 4 & 5 & 6 & 7 & 8 & 9 & 10\end{array}$

$\begin{array}{llllllllll}7.6 & 16.6 & 15.9 & 12.7 & 13.4 & 13.4 & 12.1 & 3.8 & 3.2 & 1.3\end{array}$

Musculo-skeletal problems

Do you suffer from musculo-skeletal disorders

(e.g. arthritis; back pain; sciatica; repetitive strain injury)?

Not at all

Very much so

$\begin{array}{llllllllll}1 & 2 & 3 & 4 & 5 & 6 & 7 & 8 & 9 & 10\end{array}$

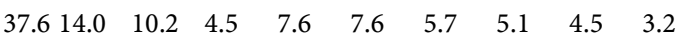

Noise

Are you exposed to noise at work?

Not at all Very much so

$\begin{array}{llllllllll}1 & 2 & 3 & 4 & 5 & 6 & 7 & 8 & 9 & 10\end{array}$

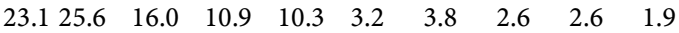

Shift work/Night work

Do you work shifts or work at night? Yes/No

Yes: $34 \%$ No: $66 \%$

Job demands

How demanding do you find your job (e.g. do you have constant pressure, have to work fast, have to put in great effort)?

Not at all demanding $\quad$ Very demanding

$\begin{array}{llllllllll}1 & 2 & 3 & 4 & 5 & 6 & 7 & 8 & 9 & 10\end{array}$

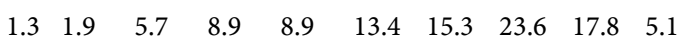




\section{Continued}

$\underline{\text { Job control and support }}$

Do you feel you have control over your job and support from fellow workers? Not at all Very much so

$\begin{array}{llllllllll}1 & 2 & 3 & 4 & 5 & 6 & 7 & 8 & 9 & 10\end{array}$

$\begin{array}{llllllllll}0.6 & 2.6 & 0.6 & 3.9 & 9.7 & 4.5 & 17.4 & 32.3 & 17.4 & 11.0\end{array}$

Perceived stress at work

How much stress do you have at work?

Very little A great deal

$\begin{array}{llllllllll}1 & 2 & 3 & 4 & 5 & 6 & 7 & 8 & 9 & 10\end{array}$

$\begin{array}{llllllllll}2.5 & 7.6 & 13.4 & 7.6 & 12.7 & 15.9 & 16.6 & 13.4 & 7.0 & 3.2\end{array}$

Job satisfaction

Are you satisfied with your job?

Not at all Very much so

$\begin{array}{llllllllll}1 & 2 & 3 & 4 & 5 & 6 & 7 & 8 & 9 & 10\end{array}$

$\begin{array}{llllllllll}3.8 & 0.6 & 3.2 & 4.5 & 14.6 & 9.6 & 23.6 & 23.6 & 11.5 & 5.1\end{array}$

Physical and mental fatigue

How physically or mentally tired do you get at work?

Not at all tired

Very tired

$\begin{array}{llllllllll}1 & 2 & 3 & 4 & 5 & 6 & 7 & 8 & 9 & 10\end{array}$

$\begin{array}{llllllllll}4.5 & 6.4 & 12.1 & 8.9 & 13.4 & 13.4 & 19.7 & 15.3 & 3.8 & 2.5\end{array}$

Illness caused or made worse by work

Have you had an illness (either physical or mental) caused or made worse by work?

Yes $16.6 \%$ No $83.4 \%$

Presenteeism

Do you ever come to work when you are feeling ill and knowing you can't

do your job as well as you would like to?

Yes-52.2\% No $47.8 \%$

Efficiency at work

How efficiently do you carry out your work?

Not very efficiently Very efficiently

$\begin{array}{llllllllll}1 & 2 & 3 & 4 & 5 & 6 & 7 & 8 & 9 & 10\end{array}$

$\begin{array}{llllllllll}0 & 0 & 0 & 0.6 & 1.3 & 4.5 & 15.3 & 36.9 & 26.8 & 14.6\end{array}$

Work-life balance

Do you find your job interferes with your life outside work or your life outside of work interferes with your job?

\begin{tabular}{llllllllll}
\multicolumn{2}{l}{ Never } & & & & & & & & Very often \\
1 & 2 & 3 & 4 & 5 & 6 & 7 & 8 & 9 & 10 \\
10.8 & 12.1 & 15.3 & 10.2 & 11.5 & 12.7 & 10.2 & 12.1 & 3.2 & 1.9
\end{tabular}

Happy at Work

Are you happy at work?

Never $\quad$ Very often

$\begin{array}{llllllllll}1 & 2 & 3 & 4 & 5 & 6 & 7 & 8 & 9 & 10\end{array}$

$\begin{array}{llllllllll}0.6 & 2.6 & 1.9 & 5.8 & 9.6 & 8.3 & 17.3 & 30.8 & 16.7 & 6.4\end{array}$

Anxious/Depressed because of work

Are you anxious or depressed because of work?

Never $\quad$ Very often

$\begin{array}{llllllllll}1 & 2 & 3 & 4 & 5 & 6 & 7 & 8 & 9 & 10\end{array}$

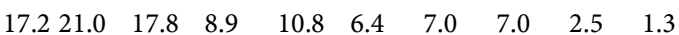

Absenteeism

Approximately how many days sick leave have you had in the last 12 months? Mean $=3.39$ days 
tors of stress at work. Job satisfaction was correlated with positive personality, positive health-related behaviors, low noise and high control/support. Multiple regression showed that only high control/support remained as a significant predictor of job satisfaction. A similar procedure was applied to the negative (anxiety/depression due to work) and positive outcomes (happiness at work). Anxiety/Depression were predicted by lack of control/support and stress at work, whereas happiness reflected job satisfaction.

\section{Discussion and Conclusion}

This is the first international survey to investigate the wellbeing of business outsourcing staff. This was done with a short online survey (SWELL) which measured positive and negative aspects of wellbeing and examined the wellbeing process. The results showed that this group of workers reported high levels of stress and mental health problems but also had high levels of job satisfaction and happiness at work. Stress was predicted by job demands and lack of control/ support. Anxiety/Depression were also predicted by lack of control/support and by stress at work. This suggests that the key dimensions to assess are perceived stress at work, which will be predicted by job demands, and control/support. The presence of control and support increases job satisfaction which is then the key predictor of happiness at work.

The present methodology had a number of important features. The survey was short and multi-variate analysis allowed identification of key predictor variables. Further analyses can easily be conducted on this type of dataset. Other outcomes (e.g. absenteeism; presenteeism; performance efficiency; and musculoskeletal disorders) could have been analysed using the same approach. In addition, a "combined effects" approach (Smith, McNamara, \& Wellens, 2004) could have been adopted to examine the additive effects of risk factors. It is also possible to use the data to examine a case definition of occupational stress (Cox, Griffiths, \& Houdmont, 2006). Case definition of stress requires (1) reporting of a high level of stress, (2) reporting of a significant outcome such as mental health problem due to work, and (3) the absence of confounding factors that could account for the stress at work (e.g. stress outside of work). The same approach can be used to look at cases of high positive wellbeing.

Although the present survey has many positives there are also some future changes needed. Most of these will be very easy to achieve and will not lead to a large increase in the length of the questionnaire. For example, it would be better to ask about physical fatigue, mental fatigue and emotional fatigue separately rather than using a general fatigue question. Work-life balance could also be sub-divided into work interfering with life and, secondly, life interfering with work.

This article describes a new measure of wellbeing at work, the Smith Wellbeing Questionnaire (SWELL). This questionnaire is free to use and is shown in the paper. It has good psychometric properties, measures positive and negative aspects of wellbeing and is based on a simple model of the wellbeing process. It 
takes less than 10 minutes to complete and it can be combined with collection of sample specific information. The study was the first to examine the wellbeing of business outsourcing staff and the findings confirmed that they are another sector at risk of high levels of stress. Prevention and management of this stress is now a key issue for practitioners.

\section{Acknowledgements}

We would like to thank ActiveOps for assistance with recruitment of the participants.

\section{References}

Cox, T., Griffiths, A., \& Houdmont, J. (2006). Defining a Case of Occupational Stress. Sudbury: HSE Research Report 449.

Diener, E., Suh, E. M., Lucas, R. E., \& Smith, H. L. (1999). Subjective Wellbeing: 3 Decades of Progress. Psychological Bulletin, 125, 276-302. https://doi.org/10.1037/0033-2909.125.2.276

Mark, G. M., \& Smith, A. P. (2008). Stress Models: A Review and Suggested New Direction. In J. Houdmont, \& S. Leka (Eds.), Occupational Health Psychology: European Perspectives on Research, Education and Practice. Vol. 3. EA-OHP Series. Nottingham: Nottingham University Press, 111-144.

Mark, G., \& Smith, A. P. (2011). Effects of Occupational Stress, Job Characteristics, Coping and Attributional Style on the Mental Health and Job Satisfaction of University Employees. Anxiety, Stress and Coping, 25, 63-78. https://doi.org/10.1080/10615806.2010.548088

Mark, G., \& Smith, A. P. (2012). Occupational Stress, Job Characteristics, Coping and Mental Health of Nurses. British Journal of Health Psychology, 17, 505-521. https://doi.org/10.1111/j.2044-8287.2011.02051.x

Smith, A. P. (2010). From the Brain to the Workplace: Research on Cognitive Fatigue in the Laboratory and Onboard Ship. In P. Ackerman (Ed.), Cognitive Fatigue: Multidisciplinary Perspectives on Current Research and Future Applications (Chapter 14, pp. 291-305). Washington: American Psychological Association.

Smith, A. P., Wadsworth, E. J. K, Chaplin, K., Allen, P. H., \& Mark, G. (2011). The Relationship between Work/Well-Being and Improved Health and Well-Being. Report 11.1 IOSH. Leicester.

Smith, A., Johal, S. S., Wadsworth, E., Davey Smith, G., \& Peters, T. (2000). The Scale of Occupational Stress: The Bristol Stress and Health at Work Study. Sudbury: HSE Research Report 265.

Smith, A., McNamara, R., \& Wellens, B. (2004). Combined Effects of Occupational Health Hazards. HSE Contract Research. Report 287. HSE Books.

Watson, D., Clark, L. A., \& Tellegen, A. (1988). Development and Validation of Brief Measures of Positive and Negative Affect: The PANAS Scale. Journal of Personality and Social Psychology, 54, 1063-1070. https://doi.org/10.1037/0022-3514.54.6.1063

Williams, G. M. (2012). Developing Short, Practical Measures of Well-Being. In M. Anderson (Ed.), Contemporary Ergonomics and Human Factors 2012 (pp. 203-210). London: Taylor \& Francis. https://doi.org/10.1201/b11933-52

Williams, G. M., \& Smith, A. P. (2016). Using Single-Item Measures to Examine the Relationships between Work, Personality, and Well-Being in the Workplace. Psychology: 
Special Edition on Positive Psychology, 7, 753-767.

https://doi.org/10.4236/psych.2016.76078

Williams, G., \& Smith, A. P. (2013). Measuring Wellbeing in the Workplace: Single Item Scales of Depression and Anxiety. In M. Anderson (Ed.), Contemporary Ergonomics and Human Factors 2013 (pp. 87-94). London: CRC Press: Taylor \& Francis. https://doi.org/10.1201/b13826-21

\section{Scientific Research Publishing}

Submit or recommend next manuscript to SCIRP and we will provide best service for you:

Accepting pre-submission inquiries through Email, Facebook, LinkedIn, Twitter, etc. A wide selection of journals (inclusive of 9 subjects, more than 200 journals)

Providing 24-hour high-quality service

User-friendly online submission system

Fair and swift peer-review system

Efficient typesetting and proofreading procedure

Display of the result of downloads and visits, as well as the number of cited articles Maximum dissemination of your research work

Submit your manuscript at: http://papersubmission.scirp.org/

Or contact psych@scirp.org 